\title{
Lessons from livelihood
} interventions that increase the resilience of populations to

\section{droughts in Afghanistan and other FCAS}

Roz Price

Institute of Development Studies

23 November 2021

\section{Question}

- What are the lessons learned identified in the literature on livelihood interventions and support that contribute to increasing the medium to long-term resilience of populations during and immediately after droughts in FCAS settings? With a focus on Afghanistan, rural livelihoods and vulnerable populations (including women, people with disabilities and youth).

\section{Contents}

1. Summary

2. Rural livelihoods in Afghanistan

3. Insights and lessons learned from programming

4. References

The K4D helpdesk service provides brief summaries of current research, evidence, and lessons learned. Helpdesk reports are not rigorous or systematic reviews; they are intended to provide an introduction to the most important evidence related to a research question. They draw on a rapid deskbased review of published literature and consultation with subject specialists. 


\section{Summary}

Creating and protecting more resilient rural livelihoods is seen as being key to advancing Afghanistan's development and improving its reslience to climate change impacts, particularly drought. This rapid review draws on policy and programme information from donor and multilateral organisations and some academic literature to identify best practices and lessons learned on interventions to support livelihood resilience (to drought) in Afghanistan. Where possible, final project evaluations were utilised. Some broader recommendations and insights are taken from other fragile and conflict-affected situations (FCAS) and also from resilience and livelihoods interventions in Afghanistan that are not necessarily explicitly linked to dought. Papers in this review highlight the prominence of 'resilience' in donor interventions, but that there is a continued lack of clarity on how it should be measured or evaluated and there remains "insufficient empirical work on the characteristics of resilient livelihoods" (Stites \& Bushby, 2017, p. v).

This rapid review uses broad search categories and approaches, including database and website searches and snowballing of references. Inclusion and exclusion criteria were developed iteratively, with abstracts and documents assessed to find the most relevant papers. Donor databases were searched for relevant information, including the International Fund for Agricultural Development (IFAD), the Swedish International Development Cooperation Agency (Sida), United Sates Agency for International Development (USAID), World Bank, World Food Programme (WFP). A key source of information was the Secure Livelihoods Research Consortium (SLRC), an eight year global research programme exploring livelihoods, basic services and social protection in conflict-affected situations. A number of SLRC papers were deemed relevant to this review and included, including systematic reviews carried out in 2012 and 2017 that explored the evidence on a number of livelihood strategies in relation to FCAS (see Mallet \& Slater, 2012 and Stites \& Bushby, 2017).

There is a large, burgeoning literature on livelihood interventions in FCAS and specifically Afghanistan. Much of the literature identified through this rapid review is donor-based evaluations of projects in Afghanistan. However, many of these evaluations are mainly concerned with project outputs and issues of implementation and process, particularly those relating to routine project monitoring and evaluation in fragile situations. Less robust information was provided on the success/results, appropriateness and lessons learned from the interventions themselves. Gender considerations and a focus on targeting those most vulnerable to climate change impacts and shocks (such as subsistence farmers, youth and women) in interventions were touched on in evaluations and literature. However, detailed information or disaggregation of findings by population groups were not always forthcoming, especially for people with disabilities.

This review shows a breadth of resilience and livelihood programming in Afghanistan, especially aimed at agriculture and livestock. However, evaluations are not always clearly defined in terms of the 'success' or 'resilience' of interventions or the lessons learned. It was not possible to explore all the evidence and evaluations identified; priority was given to systematic reviews of multiple interventions (such as in the SLRC paper by Stites \& Bushby, 2017) and evaluations with clear lessons on intervention success. A Best Buys in improving incomes for the poorest, focusing on social protection and agriculture paper provided by FCDO also offered some guidance on the types of livelihoods to focus on (FCDO, 2021). Although it was not possible given the rapid nature of this review to explore all livelihood interventions covered. Furthermore, as this paper covers a broad range of interventions and much of the evidence consists of micro- 
level case studies, the lessons gleaned from the literature must be taken as illustrative, and in no way comprehensive or conclusive. It is also important to consider the highly context-specific nature of climate change effects, livelihood characteristics and interventions.

\section{Rural livelihoods in Afghanistan}

\section{Climate change impacts}

Afghanistan is one of the most vulnerable countries to climate change impacts due to a combination of political, geographic, and social factors. It ranked $175^{\text {th }}$ out of 182 countries in the 2019 ND-GAIN Index. ${ }^{1}$ Afghanistan is highly dependent on agriculture for livelihoods, particularly livestock production, with over $80 \%$ of Afghans directly involved in agricultural production (Kawasaki, et al., 2012 cited in Hutchens et al., 2018, p. 135). Wheat is the primary staple crop for human nutrition in Afghanistan, and is also the primary source of winter fodder for livestock (along with local alfalfa and clover varieties) in most Afghan farming systems (Hutchens et al., 2018).

The World Bank Group and Asian Development Bank's (ADB) recent climate risk country profile for Afghanistan summarises the following points (World Bank Group \& ADB, 2021, p. 2):

- Afghanistan faces rates of warming higher than the global average with a potential rise of $1.4^{\circ} \mathrm{C}-5.4^{\circ} \mathrm{C}$ by the 2080 s and the 2090 s, compared with the baseline of $1986-2005$. The range of possible temperature rises highlights the significant differences between $21^{\text {st }}$ century emissions pathways.

- Rises in the annual maximum and minimum temperature are projected to be greater than the rise in average temperature, likely amplifying the pressure on human health, livelihoods, and ecosystems.

- Changes to Afghanistan's rainfall regime, and hence water resources, are highly uncertain, but an increase in the incidence of drought conditions is very likely, and the shifts in the runoff regime have already been documented. Over the long-term, loss of glaciers could fundamentally disrupt regional water and hydropower supplies.

- Arid land-cover is likely to expand either side of the Hindu Kush, leading to shifts in ecosystems and potentially loss of biodiversity.

- Temperature increases are likely to place strain on urban dwellers, outdoor laborers, and the country's energy network, with increased risk of heat-related sickness and fatalities under all emissions pathways.

- Comprehensive understanding of current and future climate risks across multiple sectors is severely constrained by a lack of data and research.

Two primary types of drought affect Afghanistan: "meteorological (usually associated with a precipitation deficit) and hydrological (usually associated with a deficit in surface and subsurface water flow, potentially originating in the region's wider river basins). These issues may also

\footnotetext{
1 The ND-GAIN Index ranks 182 countries using a score which calculates a country's vulnerability to climate change and other global challenges as well as their readiness to improve resilience. The more vulnerable a country is the lower their score. https://gain.nd.edu/our-work/country-index/
} 
combine with land and crop management practices to result in agricultural drought" (World Bank Group \& ADB, 2021, p. 12). Persistent droughts have previously impacted livestock numbers, staple crops (such as wheat) production and reduction in irrigated agricultural production area. Furthermore, cultivation of opium poppy is correlated with drought conditions due to its resilience to drought, and has seen a resurgence in recent years (Parenti, 2015 cited in World Bank Group \& ADB, 2021, p. 17). Afghanistan is also a net food importer in financial value terms, and as such is vulnerable to external price shocks and impacts of climate change on other exporter countries. Other issues to consider include the potential impacts of climate change on the health and productivity of the workforce, national food consumption patterns, growing seasons of crops, alterations to carbon dioxide availability, precipitation and temperatures, water resource availability and seasonality, soil organic matter transformation, soil erosion, changes in pest and disease profiles, and land degradation (World Bank Group \& ADB, 2021, p. 18).

\section{Vulnerable groups}

The level of impacts and coping strategies of populations to climate impacts "depends heavily on their socio-economic status, socio-cultural norms, access to resources, poverty as well as gender" (World Bank Group \& ADB, 2021, p. 21). Women and children are among the highest atrisk groups, as well as people with disabilities (the Red Cross Red Crescent Climate Centre, 2021). Key factors that account for the differences between women's and men's vulnerability to climate change risks include: "gender-based differences in time use; access to assets and credit, treatment by formal institutions, which can constrain women's opportunities, limited access to policy discussions and decision making, and a lack of sex-disaggregated data for policy change" (World Bank Group \& ADB, 2021, p. 21).

Climate change most directly and heavily affects the poorest people in Afghanistan-particularly subsistence farmers and pastoralists who are already living on marginal land. A recent climate risk assessment for Afghanistan by the Red Cross Red Crescent Climate Centre (2021) highlights the intersectional nature of vulnerability to climate change, with many people being in overlapping categories of vulnerability, but also that vulnerability can change over time. For example, women from ethnic groups, such as the Pashtun, are often excluded from education opportunities and employment and are thus at higher risk of the impacts of climate change, not least because they have very low levels of awareness on climate risks.

\section{Livelihoods and resilience}

\section{Livelihoods and coping mechanisms in Afghanistan}

A SLRC working paper by Huot and Pain (2017) reports on the third wave of a longitudinal panel study tracing the outcomes of rural Afghan households over a 14-year period. Drawing on a subset of the original panel households in Herat, Kandahar and Sar-i-Pul provinces from 2002 and 2008-09, this report focuses on specific households in Sayyad in Sar-i-Pul, one of the most impoverished provinces in Afghanistan. The paper details the various shocks households have experienced, the coping strategies they have employed, and how or why conditions have improved or declined.

To summarise, although many households in Sar-i-Pul "have recovered since 2008-09, life remains deeply uncertain with many moving in and out of poverty within seasons and between 
years - a classic form of poverty 'churning'. The ability to survive from agricultural activities alone is rare, and requires extensive land and livestock holdings. Only those with access to sufficiently diverse income sources, enough labour, or the right connections to secure off-farm jobs, have any degree of livelihood security" (Huot \& Pain, 2017, p. 37).

In their conclusion the authors bring out larger lessons that can be drawn from the research and applied to other contexts (Huot \& Pain, 2017, pp. 35-37):

- Incoherence between the rhetoric of agricultural policy and evidence on the ground. Rural households engage in a number of coping strategies. These coping strategies, while varied, are largely non-farm based; in almost no cases are households in a position to survive, let alone improve their circumstances, through agricultural pursuits alone. This is not surprising given that the majority of agricultural land in the study villages is rainfed $(7,700$ out of a total 8,523 jeribs), and that the proportion of landless households varies from $74 \%$ to $87 \%$ of each village. Thus, most households seek livelihood security from activities outside the rural economy, depending largely on remittance income and employment in urban sectors.

- For most households, life is characterised by risk and uncertainty. Marginal conditions demand household mobility. Some have permanently left the village, but many more travel to Iran or Mazar on a seasonal basis for work. Working in the brickfields of Mazar carries risks, however, as a household can easily get trapped in cycles of debt, either becoming bonded labour for the brick kilns or being forced to sell assets in order to repay their debt. There is little choice in either of the options and both carry substantial risks.

- Marginality has also contributed to a resurgent opium economy. Opium poppy cultivation has increased the demand for farm labour and has increased rural wages for men and women alike. With the benefits of employment and higher rural wages there is little reason to believe opium poppy production will not further expand in the future.

- Access to resources is governed by personal networks that largely exist outside the formal structure of the state and connectivity to them, few public goods can be seen as accessible to all. In the case of Sayyad, with a largely inactive and disengaged district governor and limited personal networks beyond the district, the Community Development Councils (CDC) in the villages have served as the major channel for making connections to the district and provincial level. Pre-existing village governance structures blend with the CDC as village leaders that derived their power as traditional authorities, heads of shuras (village councils), or former commanders became CDC members. It is the power and the influence of external networks that make CDCs function. Furthermore, as suggested by Coburn (2011), networks are characterised by mutual reciprocity and must be maintained through a system of rewards and benefits.

- The need for income and the scarcity of employment have contributed to reshaping gendered labour activities. While income generation by women was beginning to play a role in household recovery in 2008-09, the activities remained firmly in the realm of 'traditional' activities such as spinning wool. Male out-migration and decreasing markets for embroidery after the 2006-08 drought have enabled and encouraged women to begin sharecropping, grazing livestock, and travelling to Mazar to work in the brick kilns with their families. In the third study wave, women have begun to enter a once exclusively male space, labouring in the brick kilns of Mazar, sharecropping 
melons, and grazing livestock. While this represents a significant shift in women's economic roles within the family, inequalities persist as wage rates remain lower for women than men, and are paid to the male head of the household.

\section{Views on livelihoods and resilience}

Research by ThinkClarity (2020) for UNDP Afghanistan explores the lived experience of previous droughts in Afghanistan that underpins how people make decisions and choose to act. The research uses SenseMaker $\AA^{2}$ to collect, map, and explore narrative-based data on lived experiences of drought and resilience of 1,300 respondents in the provinces of Herat and Badghis. The findings, presented in three thematic areas - security, livelihoods, and community - highlight differences in perceived threats, sources of assistance, faith in Government and the benefit of local cooperative schemes and, in particular, identify the impact of gender, age and land tenure.

Years of conflict and repeated natural disasters have forced Afghan families and communities to be resilient. "However, their coping strategies, many of which involve selling productive assets, consuming seed stock and borrowing money, have made it increasingly difficult to continue to absorb shocks and to adapt to disruptive change... The severity of the 2018 drought in addition to the conflict has tipped many over the edge and created mass displacement" (ThinkClarity, 2020, p. 7). Internally displaced persons (IDPs) provided multiple interrelated reasons for leaving their land. This suggests that leaving and returning might be the result of a build-up of stresses across the board rather than failure to cope with a single problem (such as water security). This in turn calls for a resilience strategy that addresses many concerns (ThinkClarity, 2020, p. 53).

Other key points from the research include:

- The data shows a connection between respondents' land tenure and the way they interpret their lived experience. This in turn points to a difference in how to address/rebuild their resilience. The key issue is that 'squatters' (i.e. respondents living on common land or land with contested tenure) and those living in IDP sites appear marginalised. Many of these respondents feel more threatened by the government and are less willing to engage in community projects such as cooperatives. Whereas, landowners, wage workers, and renters who left and returned to their land - or indeed stayed throughout the drought - are confident in cooperative schemes as ways to build resilience (ThinkClarity, 2020, p. 53). While this may not be surprising, it requires trust to be rebuilt alongside - or even before - efforts to bolster resilience and also requires efforts to address concerns that local cooperative schemes may adversely impact people who do not have land titles (ThinkClarity, 2020, p. 8).

- Marginalisation is also a factor in the level of faith in (or reliance on) government and other formal organisations such as non-governmental organisations. Informal sources of assistance are more important to respondents without land title than to other respondents. All respondents felt that formal sources of assistance were important in

\footnotetext{
2 SenseMaker $\AA^{\circledR}$ is a proprietary software that enables narrative-based research in which respondents are asked to describe a relevant experience and then answer visual questions to signify what their experience means to them in their own context.
} 
helping them cope with the drought. However, squatters and IDPs were significantly more likely to draw upon additional aid from informal sources such as their wider family, Local Elders, Iman and Malik. Notably these informal sources also include armed nonstate actors (ThinkClarity, 2020, p. 52).

- Gender and age are important in determining what aspect of their livelihoods respondents were most concerned about. Men appear to be more worried about the 'economic' concern of losing water, while women are more concerned with losing their place in the community. The survey found that there was a significant generational divide in priorities - older people valued stability and the closeness of their community, younger people valued jobs and participation in an urban-centric cash economy (ThinkClarity, 2020 , p. 52). Hence, gender-specific differences in perceptions about the impact of drought and conflict and differences in generational priorities about livelihoods are important considerations in interventions (ThinkClarity, 2020, p. 55).

- Women might be becoming more engaged in (negative) coping mechanisms such as changing their labour practices to non-farming activities, and borrowing money. Respondents borrowed money twice as frequently in this drought as in the past. This behaviour may be contributing to the growth of the cash economy. However, coupled with the apparently increasing involvement of women and families in coping mechanisms, this change may run counter to the traditional Islamic ethos in Afghanistan (ThinkClarity, 2020, p. 53).

\section{Insights and lessons learned from programming}

\section{SLRC evidence on livelihood interventions in FCAS}

Stites and Bushby (2017) build on a SLRC systematic literature review carried out by Mallet and Slater in 2012, which synthesised the available evidence on livelihoods and growth in FCAS with the aim of identifying key findings, weaknesses in the literature and shedding light on the nature and composition of the evidence base. Stites and Bushby (2017) review the most salient developments in livelihood and economic growth interventions between 2012-2016 that increasingly take into account the importance of conflict sensitivity of interventions:

- Livestock and farming interventions: Supporting agro-pastoral, pastoral and agrarian livelihoods has gained increased attention in recent years due to climate change, the push for greater resilience to natural disasters, and that agricultural and pastoral livelihoods are often pursued by marginalised populations. However, context is key and such interventions must be implemented carefully and with extensive local participation in conflict-affected areas, as livestock assets can easily expose households to greater risk through theft, for example. Inequality should be an important consideration for livestock and farming interventions moving forward, as smaller stockholders have increasingly been excluded from accessing markets given wide-scale commercialisation in the sector. And there is increasing concern among actors that interventions may actually increase income inequality in these sectors, and fail to benefit the most vulnerable populations. Market expansion in FCAS has also raised new opportunities for livestock owners and farmers. But there is the need for donors to continuously evaluate the conflict context and political economy to ensure that windows of opportunity are seized. In conflict-affected 
zones, security and physical mobility for both people and animals are critical, especially in cross-border areas (Cervigni and Morris, 2016 cited in Stites \& Bushby, 2017, p. 23).

- With respect to practice, the Livestock Emergency Guidelines and Standards Report, initially published in 2009, remains a vital resource for livestock interventions in emergency contexts. But uptake of the best-practice guidelines remains ad hoc and is subject to various institutional constraints, including training limitations, institutional memory, and high staff turnover in conflict environments. Interventions often lack a rigorous assessment of the suitability of breeds within the local context and in reality, many animals die quickly and those that survive fail to reproduce at the anticipated rates (Levine, 2016 cited in Stites \& Bushby, 2017, p. 22).

- There have also been developments in seeds-and-tools interventions between 2012-2016, although the state of new evidence is limited, and there is a dearth of available robust resources overall (Carpenter, 2012 cited in Stites \& Bushby, 2017, p. 22). Carpenter's (2012 cited in Stites \& Bushby, 2017, p. 22) systematic review concludes that the assumption that seeds are always unavailable in conflict situations is untrue, and further to this that more recent seeds-and-tools programmes have had positive impacts on food security, stability and wealth. For example, in Pakistan's Swat Valley, the provision of seeds, fruit saplings and fertilisers to farmers was a key livelihood intervention following the Taliban's control of the region (Suleri et al., 2016 cited in Stites \& Bushby, 2017, p. 23). This intervention is said to have had positive impacts overall: new stores opened up in previously-remote areas as a result of the increased demand, and this may have also contributed to the shift from the production of subsistence crops to cash crops. It is worth noting that despite these successes, however, targeting of populations was problematic for this programme and small farmers in Swat Valley were seen to be generally excluded (Shah and Shahbaz, 2015 cited in Stites \& Bushby, 2017, p. 23). In northern Uganda, research reveals similar concerns about inequality in agro-pastoral interventions.

- Microfinance: Access to markets has been viewed as a critical component of livelihood support in donor programming for years. Within this area, microfinance is one of the most discussed interventions in FCAS. Ultimately, the evidence base for microfinance and microcredit programmes in FCAS appears mixed (Mallett and Slater, 2016). There are questions about how the poor are being incorporated into global markets, and the degree to which microfinance supports livelihoods of the most vulnerable populations in conflict and emergency environments. Despite this criticism, there has been a recent surge of interest in innovation in microfinance (Stites \& Bushby, 2017, p. 24).

- Making markets work for the poor (M4P): Market systems approaches (i.e. M4P) that seek to reduce poverty by increasing the ways that poor populations interact with markets, gained significant attention in 2011 and 2012, but the evidence base since then remains limited. In SLRC's systematic review by Mallett and Slater (2016), only three out of 483 studies met the criteria for inclusion. It is likely, however, that governments and donors have embraced similar principles through a focus on financial inclusion interventions in FCAS, even if evidence is lacking. Additionally, there have been some efforts to standardise M4P approaches that incorporate conflict sensitivity. Ultimately, given the dearth of recent evaluations of M4P in conflict-affected situations, it is difficult to 
assess how effectively this guidance is implemented, and how this affects the livelihoods of the most vulnerable (Stites \& Bushby, 2017, p. 24).

- Value chain development: Recent literature makes more of an effort to link the formal sector with the informal economy in global value chains, which has promising implications for the development of this area in conflict settings. Understanding who the specific value chain will benefit - and if this will exacerbate tensions - is vital and requires a deep understanding of local contexts. For example, SLRC-supported research into the informal regulation of the onion value chain in Nangarhar, Afghanistan reveals that social networks and relations are essential to trading systems and market exchange in Afghanistan (Minoia et al., 2014 cited in Stites \& Bushby, 2017, p. 24). This underscores the need for external interventions in value chains (and otherwise) to fully understand the drivers of local economies. When these conditions are understood, research shows that value chains have potential as a form of collective action against rent seeking, and help to restore social capital (Dudwick et al., 2013 cited in Stites \& Bushby, 2017, p. 24).

- Job creation and entrepreneurship interventions: The impacts of job-creation programmes on livelihoods are still largely unknown, thus interventions need to assess how conflict reconfigures and distorts labour markets and local power relations (Mallett \& Slater, 2016).

- Skills-based training and capacity-building interventions: Skill- and capacity-building training has long been a common aspect of many donor livelihood interventions, and often runs alongside interventions concurrently. The evidence reveals drawbacks to these interventions, including failing to consider participants' needs and interests; failing to assess market viability of the promoted skill; an insufficient timeline to make an impact; having a limited understanding of barriers that participants may face; and lacking strong links with financial service providers or labour markets (Crawford et al., 2015 cited in Stites \& Bushby, 2017, p. 26). Training programmes have also been critiqued for pushing western models that may not fit local contexts (Kapadia, 2015 cited in Stites \& Bushby, 2017 , p. 26), while capacity-building programmes are often overly technical and fail to recognise the complexity of local systems (Mallett and Denney, 2015 cited in Stites \& Bushby, 2017, p. 26). However, research since 2012 reveals some of the nuanced successes of skill- and capacity-building training in FCAS. One example is a recent evaluation of plant nursery interventions in Swat Valley, Pakistan, which were successful when accompanied by capacity-building training (Shah and Shahbaz, 2015). Agricultural extension practices and training on marketing products have also been viewed as complementing livestock and agrarian interventions in Uganda (Mazurana et al., 2014). Ultimately though, questions remain about who accesses training programmes, how these are publicised among local populations, and the long-term benefits of such initiatives (Stites \& Bushby, 2017, p. 26).

Further points highlighted by Maxwell et al. (2017) from SLRC research includes the importance of social capital, social networks and informal economies. As many livelihoods in FCAS are informal, and are based on the strength of social networks, familial ties and even patronage systems. Hence, understanding social networks and informal economies, structures and institutions and then using this applied knowledge to design and implement interventions is key (Maxwell et al., 2017; Stites \& Bushby, 2017). This also links to the importance of context and contextually-based assessments, as FCAS livelihood recovery programmes tend to neglect the 
context, needs and priorities of the population. Issues such as market factors, gender dimensions, and formal and informal institutions and processes play a significant role in deciding who can access and succeed in various livelihoods in FCAS (Maxwell et al., 2017).

\section{FAO Integrated Dairy Schemes (IDS) project}

Between 2005 and 2015, FAO implemented the Integrated Dairy Schemes (IDS) project, with financial support from the Afghan, German and Italian Governments and IFAD. The aim of the project was to improve food security in Afghanistan by supporting the national dairy sector through the development of IDS. An evaluation of the project carried out by Boros and McLeod (2015) reviews the IDS in Afghanistan from a gender perspective and recommends ways to consolidate and reinforce the schemes in the future. It focuses on four of the five existing IDS, located in Kabul, Balkh, Kunduz and Herat - all with different market and operating within different cultural contexts.

According to Boros and McLeod (2015, p. vii) "The IDS approach was developed by FAO, based on previous experience of the livestock sector in Afghanistan and of smallholder dairy industry development initiatives elsewhere...IDS are based on the formation of smallholder farmer cooperatives, organised at village level, which together form a dairy union at provincial level. The IDS model consists of a dairy value chain - managed by the union as an enterprise - that encompasses milk production, collection, processing and marketing of pasteurized milk and dairy products." IDS has been able to link consumer demand and small-scale dairy farming effectively in Afghanistan, and has helped milk producers to decrease milk loss, thanks to their dairy cooperatives and enterprises, as well as refrigeration systems introduced along the dairy value chain. IDS were not designed with a gender strategy, but were based on FAO's knowledge of the roles and responsibilities of women and men in Afghanistan's livestock sector.

The paper finds that there was significant and sustained cash income from "milk money" that is accruing to women and their families in rural areas of Afghanistan. This changes their lives positively both in terms of regular cash income and in empowerment and making better decisions on household food security, education and health. Other noted benefits include reduced labour for women at home for processing milk into low-value milk products. Involvement in IDS is opening up new market opportunities in the urban centres for rural families. Training under IDS in particular appeared to be crucial to women's empowerment since, in addition to improved cattle management, they learn valuable skills (Boros \& McLeod, 2015, p. vii).

The paper summarises the findings of the review into a brief checklist that could be used when planning and implementing the development of dairy value chains in developing countries, in order to make them more gender sensitive. The following are all important actions to be undertaken (Boros \& McLeod, 2015, p. 39):

- Promote an inclusive approach, focused on low-income farmers and women. This could include emphasising approaches suitable for households with limited land and small herds; deliberately targeting a diverse population in terms of gender and ethnicity; and ensuring there is diversity among the people consulted during planning.

- Ensure that the planning team is diverse and gender sensitised. A gender-balanced project team trained in gender issues is needed to design and implement a gendersensitive dairy value chain. In countries where rural women do not routinely interact with 
men, it is critical to ensure that a sufficient number of trained project staff can interact with women beneficiaries.

- Identify a legitimate entry point into the community. A gender-sensitive dairy chain, even when it is introduced with great care, may initially be an unfamiliar idea. Once implemented, it may result in cultural changes that are unpopular with some members of the community. Finding the right entry point makes it possible to interact with the community and work with them to resolve problems. Working through traditional leadership and shuras has proved to be highly effective in IDS developed to date.

- Use a participatory and culturally aware approach. A dairy chain is much more likely to be sustainable and successful if it is planned together with the local community. To plan and implement a gender-sensitive value chain requires a strong cultural awareness about appropriate ways to approach and engage women, men and youth in rural communities, and how to introduce subjects that may be sensitive. It also means designing training activities that will allow both women and men, and members of diverse ethnic and cultural groups, to participate.

\section{USAID Afghanistan Agricultural Extension Project II (AAEP II)}

In general, livestock nutrition in Afghanistan is quite poor particularly during winter, extended periods of drought, and for animals during pregnancy and lactation (Ates et al., 2016 cited in Hutchens et al., 2018, p. 136). A journal paper presents preliminary results from the USAID funded Afghanistan Agricultural Extension Project II (AAEP II), which aimed at improving agricultural research and extension capacity in Afghanistan and was conducted in 17 provinces and 143 districts. "At the core of the AAEPII project was an extension model that focused on bottom-up program prioritization, empowered lead farmers as educators, and encouraged public extension agents to increase their field-based interactions with farmers and other private sector stakeholders" (Hutchens et al., 2018, p. 136). As a capacity building programme, AAEPIl focused on the training-oftrainers approach, with extension agents and at times, lead farmers, being the primary training participants.

Applied trials and field demonstrations were carried out for a variety of forage and fodder crops with tolerance to limited water and fertility resources. The paper presents recommendations for building the capacity of Afghanistan to equip farmers with the knowledge and technologies necessary to respond to constraints to forage and fodder production. Namely (Hutchens et al., 2018, p. 138):

- Programmes should seek to develop grassroots farmer organisations to support extension efforts at the local level and to lobby the Ministry for Agriculture, Irrigation and Livestock (MAIL) for additional support for extension at the provincial and district level, particularly in traditionally underserved villages.

- To reach a greater number of women in the agriculture sector, MAIL should prioritise employment and capacity building of women in extension and research positions.

- Institutional capacity building efforts should prioritise the provision of resources for public extension and research staff (transportation, supplies, facility and machinery maintenance, etc.). This could be supported through reform of the policies currently limiting MAIL research and extension managers from reinvesting returns from products 
generated on MAIL research and demonstrations facilities back into operations and maintenance of the facilities.

\section{UNDP Afghanistan Climate-Induced Disaster Risk Reduction Project (CDRRP)}

A number of the papers highlight the continued focus of many interventions and programmes solely on strengthening agricultural livelihoods' resilience in Afghanistan, despite evidence and baseline information to the contrary. For example, a recent mid-term evaluation of UNDP Afghanistan's Global Environment Facility (GEF)-funded Climate-Induced Disaster Risk Reduction Project (CDRRP) highlights that "The relevance of the livelihoods interventions to disaster resilience is tenuous; the exclusive focus on agriculture is contrary to the recommendations of the baseline study and its finding that the large majority of rural household income derives from non-agricultural sources. [The] Selection of MAIL as the main implementing partner almost certainly contributed to this emphasis on agriculture" (Goss \& Wahdati, 2021, p. 10). The mid-term evaluation recommends that future projects should carefully consider the "relevance of agricultural interventions to their overall objective and the needs of the target population" (Goss \& Wahdati, 2021, p. 10). The evaluation also notes several lessons learned from previous UNDP managed Community-Based Agriculture and Rural Development Projects also implemented by MAIL, that could have benefitted CDRRP's design. These lessons include (Goss \& Wahdati, 2021, p. 43):

- The Mid-Term Evaluation of CBARD-East found that agriculture was a minority income source for lead farmers, beneficiaries and non-beneficiaries in Nangarhar province, in line with the findings of the CDRRP baseline survey.

- A review of the cost-effectiveness of different livelihoods interventions in the mid-term review notes that macro greenhouses were already identified as one of the least costeffective interventions under CBARD, yet they have been repeated in CDRRP and allocated $48 \%$ of the total livelihoods budget to date. The mid-term review includes "reasonable estimates of costs and benefits" for four other types of intervention: dairy toolkit (173\% undiscounted annual Return on Investment (ROI), with average payback period of 7 months); micro greenhouses (29\% ROI, payback over 3 years and 5 months); vegetable trellising ( $87 \% \mathrm{ROI}$, payback over 1 year and 2 months); and kitchen gardens (262\% ROI, payback over 5 months) (see Table 10 in Goss \& Wahdati, 2021, p. 70).

- The Mid-Term Evaluations of both CBARD-West and CBARD-East identified the lack of a proper project database as a significant monitoring weakness, and the same issue is identified for CDRRP.

The mid-term evaluation survey also found that "the interventions are well received in the communities and, as far as can be judged from the limited data available, the livelihoods interventions seem to be making a useful contribution to household incomes. If this were an agricultural livelihoods project, it would be highly rated and the recommendations would simply focus on improving the monitoring of financial impacts and adjusting the intervention mix towards the most cost-effective activities" (Goss \& Wahdati, 2021, p. 83). 


\section{UNDP Climate Change Adaptation Project (CCAP)}

The Strengthening the resilience of rural livelihood options for Afghan communities in Panjshir, Balkh, Uruzgan and Herat Provinces to manage climate change-induced disaster risks project (also known as also known as the Climate Change Adaptation Project (CCAP)) was funded by the Least Developed Countries Fund (LDCF) established by the GEF and implemented by UNDP Afghanistan between 2014-2019. The project focused on integrating climate change risk and variability into local planning and budgeting processes; enhancing and diversifying rural income and livelihood opportunities for vulnerable communities; and rehabilitating and improving productive irrigation infrastructure (UNDP Afghanistan, 2019, p. 9).

CCAP took a number of actions to prioritise needs of women and promote their participation in project activities. These included: giving priority to those communities and districts who were willing to allow participation of women in the project activities; giving priority to women in climate change awareness and livelihood skills training; with support from the Ministry of Women Affairs and Community Development Councils (CDCs), women were organised into Self-Help Groups to manage food processing activities and, later, to run food processing centres; funding for green houses was provided on the written condition that women will be employed as wage earners at these greenhouses; and several livelihood outputs such as kitchen gardening, honey beekeeping, solar dryer and raisin drying room were particularly suitable for women, as these activities could be undertaken inside the house (UNDP Afghanistan, 2019, p. 33).

Lessons learned and best practices from the final evaluation mostly revolve around project processes, recruitment and management arrangements and micro-issues, but also include some thematic insights. Lessons include (UNDP Afghanistan, 2019, pp. 58-60):

- CCAP learned from experience that self-help group activities should be of a sizeable scale to ensure good quality of products for marketing and to reap economies of scale for making profit. Inadequately equipped and trained groups could not earn enough profit, as they faced problems in generating demand for their products and keeping the costs low.

- CCAP learned that greenhouses for demonstration purposes cannot be managed well and cannot be run profitably if the size of a greenhouse is too small. However, bigger greenhouses run the risk of transferring a big investment to a single farmer who benefits from it at the cost of small farmers. Projects should make sure that profits of such greenhouses are equitably distributed among the women workers of the greenhouse.

- Linking with private sector can increase profitability and sustainability of small enterprises such as greenhouses. Cultivation of high value and rare crops and medicinal plants in greenhouses requires special marketing arrangements, as local consumption of the produce is not guaranteed.

- Women in remote areas are not allowed to meet project staff. The best solution to approach these women is to train master trainer women in approachable villages and incentivise them to train women in remote villages.

- Honey beekeeping is one of the most suitable livelihood interventions for women. A group of 2-3 women need hives and some training to start this enterprise in their homes. Women can also be trained on compost making, which increases farm production. Drip irrigation is helpful to women, as they can manage this form of irrigation themselves. 
- It was difficult to organise women into a group in the beginning. Once a group begins to show income generation potential, men become more willing to allow women to participate in the group. Women generally show more responsibility in income generation activities than men.

\section{Key issues highlighted in SLRC Afghanistan research}

\section{Expectations of programming in Afghanistan vs realities on the ground}

Pain, Jackson, Huot and Minoia (2017) in a SLRC briefing paper draw from a three year research programme examining how people make a living in rural Afghanistan and the role that government, aid agencies, markets and the private sector have played in this. They present lessons from these insights:

- There is a huge gap between policy models and programme theories of change as to how things should work in Afghanistan's sub-national governance, markets and village life, and the reality (Pain et al., 2017, p. 1).

- There has been enormous donor investment in an unsuccessful strategy for agriculturally-led economic growth that is out of step with Afghan realities:

Evidence points to a large and growing landless rural population who do not and cannot in the future derive much of a living from being there, but survive on remittance income from local and distant migration. In part these people stay due to the lack of options to go elsewhere, but it also seems to be a response to risk and deep insecurity through investment in social relationships: the mutual dependencies of poverty and a strong distributional economy provide certain - albeit limited - entitlements not available elsewhere. Yet the view that agriculture will drive transformation for Afghanistan persists, for example in the 2014 Agricultural Sector Review (ASR) (Pain et al., 2017, p. 2).

- "The markets and private sector imagined in donor models and programmes bear little relation to how things in Afghanistan actually exist and work: Market relations at all levels are heavily socially embedded, structured by gender, identity and place. At lower levels, personalised relationships determine access to informal credit based on trust to lubricate the working of markets. Here it is credit in social terms - the reputation for fair and honest dealing - that is essential. It is assumed by the ASR that it is lack of formal credit that constrains market driven agriculture. But, as SLRC research into the regulation of Nangarhar's onion market makes clear, the demand for formal credit is more likely to be an outcome of the growth of informal credit relations than the means by which credit supply grows" (Pain et al., 2017, p. 2).

- Access to public goods has improved, but is uneven; village elites and 'networks of access' profoundly affect the ability of Afghans to access public goods and economic opportunities (Pain et al., 2017, p. 1): It is misleading to see education, health and safe drinking water as public goods available to all. Cultural values mediate availability, as the contrast between Kandahar and Herat in access to education for women makes clear. But equally significant is the role of village elites and 'networks of access' (Pain et al., 2017, p. 3). Findings from SLRC's village context work point to a more general lesson about the incoherence of interventions and design assumptions with existing structures of accountability. For example, a village traditional leader is often also the head of the CDC. 


\section{Micro-finance and self-employment/entrepreneurship may not be relevant for FCAS}

Shaw and Ghafoori (2019) in a SLRC working paper explore the key role of informal credit in social structures in two villages in Herat, Afghanistan. However, there is little recognition or understanding of informal credit in policy-making and programming (Minoia \& Pain, 2017). Within Afghanistan's deeply socially embedded economy, informal credit is a key mechanism through which markets operate and through which the distributional economy provides access to land, labour and income for rural households. The results of this study emphasise the central and uniquely important role that informal credit plays in Afghanistan's distributional economy and in affording social protection at the village level. The safety net that informal credit provides often prevents large sections of the rural population from needing to resort to damaging coping strategies in the wake of any number of potential shocks. Households that are managing or thriving through the informal credit system are able to do so primarily because of regular incomes from Iran. Furthermore, what is clear is the centrality of informal credit to the social fabric of village life (Shaw \& Ghafoori, 2019, p. 26).

Given that any attempt to influence informal credit systems directly is unlikely to succeed, the authors are loath to formulate recommendations around informal credit directly. They instead conclude with tentative recommendations that aim to situate informal credit within its broader context (Shaw \& Ghafoori, 2019, p. 27):

- "Microcredit and other formal credit programmes must invest in properly understanding local economies and village contexts if they are to appreciate the existing demands on household funds. External initiatives will always overlay existing informal practices rather than substitute for them.

- That said, agricultural credit may complement existing practices by offering what informal credit is less able to achieve in helping to pay for seeds and important inputs as well as to lease land where it is in short supply. Despite extreme pressures on households, many households do seasonally have surplus resources and there is scope for micro-insurance and rotating savings/self-help groups to complement informal credit practices. Migration may provide a greater role for rotating savings and credit associations (ROSCAs), selfhelp groups or similar micro-finance initiatives to support women and women-headed households.

- Migration to Iran and elsewhere is no longer an exceptional or occasional livelihood strategy. Alongside recognising the importance of this income to the entire rural population and to the distributional economy, every effort should be made to protect the interests and safety of migrants.

- Wider recognition of the importance of informal credit to the distributional economy should encourage policy-makers to not always see debt as problematic and appreciate the role and value of credit connections in understanding what may superficially be viewed as irrational behaviour or unintended programme outcomes."

According to Gunasekara's (2020, p. iv) synthesis paper of SLRC research in Africa and Asia, there are four main livelihood strategies that are available to people living in conflict-affected areas:

1. migrating for work, both within and outside the country

2. self-employment, either in agriculture, other products, or petty trade 
3. casual waged labour in agriculture and/or non-agriculture sectors

4. living off borrowings or debt.

Gunasekara's (2020) paper lays out the 'paradox of livelihood interventions' as an example to show where the underlying conceptual work of development thinking has not adequately gauged what exactly happens to people's livelihoods in conflict-affected settings. In particular, in the contexts studied during phase II of SLRC's research, microfinance-driven self-employment appears to be the dominant post-war livelihood recovery intervention. Gunasekara (2020, pp. 1920) concludes with the following stylised facts about finance-driven self-employment and entrepreneurship:

- Finance-driven self-employment is a short-term subsistence activity for people in conflictaffected areas. As such, assumptions and modalities used to promote conventional entrepreneurship do not apply. In this context, self-employment is not 'realising a bright business idea' but the 'only option' to make ends meet, and individuals may take up many different self-employment initiatives within a span of a couple of years, moving to producing a different product when one fails to bring income.

- Microentrepreneurs have a very localised market and their buyers are often members of the community or those living in neighbouring areas. Their customers have limited purchasing power which determines the price and quantity of sales. And they compete in a market that is saturated with the products of other microentrepreneurs with no one to purchase them.

- Microentrepreneurs in conflict-affected areas often lose out when markets are 'opened up' in the aftermath of war and conflict. As a result, they become even more risk averse in trying new products or innovations.

- Self-employed individuals in conflict-affected areas face numerous challenges in accessing markets as well as promoting their products. They have difficulty ascertaining the 'right market'. However, those who receive prior training on marketing perform better.

- Microfinance funds micro- and small enterprises and agricultural units that are very small, and which operate below a minimum efficient scale. While there are other reasons that prevent microenterprises from scaling up such as lack of access to markets, not knowing the target market and open market forces that hinder small enterprises, the finance model itself seems to be built to prevent self-employment ventures from scaling up.

- Self-employed individuals tend to 'get the loan and start making and selling something' instead of planning out their business. They receive no guidance on what to produce, who is the targeted consumer, where this consumer is, who else is producing the same product, who the other market players are and how to access them.

- The challenge faced by microentrepreneurs in scaling up their ventures is by-design, and it eventually causes such businesses to fail. Because they are very small and lowproductivity agricultural or non-agricultural ventures, the micro-loans do very little to increase output and scale up.

Suggestions on 'how to do things differently' for microfinance-driven self-employment put forward by Gunasekara (2020, pp. 25-26) include: 
- Introduce the 4Ps: product, price, place and promotion: National planners and development practitioners may find the tools offered by the 4Ps marketing mix helpful in making improvements to microfinance-driven self-employment programmes.

- Encourage local, community-driven financial institutions: The case studies point to a few positive experiences with local and community-based financial institutions. The first type is formal but local credit cooperatives. They are rarely short-term or profit-driven but are willing to use subsidies or investment in order to support the local economic development process (e.g. in Vietnam). The case studies also point to a number of informal community arrangements as well (e.g. in Sri Lanka). The case study on the importance and the social embeddedness of informal credit in rural Afghanistan also contends that governments should resist attempts to formalise, institutionalise or regulate these sort of community mechanisms (Shaw and Ghafoori, 2019).

\section{Recommendations for markets and private sector development}

Markets and private sector development are considered central to the recovery of economies and people's livelihoods after conflict (Mallet \& Pain, 2018). But the specific ways in which they shape this process, and the question of how governments and development partners might best support market recovery, are patchily evidenced and poorly understood. Mallet and Pain's (2018) Policy Insights paper summarises the main findings and policy recommendations emerging from a synthesis of the SLRC's investigation of the role that markets play in processes of post-conflict livelihood recovery, drawing also on key evidence and insights from the wider literature.

Key policy recommendations emerge, which are intended to act as a set of principles for policy makers to keep in mind as they design interventions, include (Mallet \& Pain, 2018):

1. Pay closer attention to the substance and trajectories of economic transitions out of war. Do not assume that peace dividends automatically trickle down evenly throughout society. Linked closely to this is a need to better understand how transitions, and processes of recovery more broadly, work differently for different people. (p. 268)

2. Stop treating everyone as entrepreneurs-in-waiting. Start engaging with the 'demand side' of markets. Much post-conflict economic policy is based on the principle of promoting people's insertion into markets, with "supply-side" programming to enhance what individuals can bring to the market receiving the lion's share of attention. It includes measures like vocational training, skills development, microcredit and enterprise support. SLRC and other evidence is finding that these are often not the most appropriate vehicles for post-conflict recovery. Instead, engaging the demand side of markets to change the way the market itself works is needed. This means looking more closely at the economic opportunities available to people, including the way they are distributed across society. (p. 269)

3. Build more detailed, contextual understandings of how markets are regulated. If thinking and working more on the demand-side dimensions of markets is any kind of possibility, one starting point must be to develop fi ne-grained understandings of how they function in the first place, eventually leading to a diagnosis of what realistic market reform might look like. (p. 270)

4. Think and work politically to secure more people-centred market outcomes. Once policy makers are armed with a rigorous power-based analysis of how 'real markets' are 
structured and regulated, the next question is what to do with that information. Several things already being done could realistically be tweaked, strengthened or applied differently, such as M4P ('make markets work for the poor').

\section{References}

Boros, R. \& McLeod, A. (2015). Empowering women in Afghanistan: Reducing gender gaps through Integrated Dairy Schemes, Rome: Food And Agriculture Organization Of The United Nations. https://www.fao.org/3/i4585e/i4585e.pdf

FCDO. (2021). Best Buys in improving incomes for the poorest, focusing on social protection and agriculture, Economics and Evaluation Directorate \& Research and Evidence Division, Foreign Commonwealth and Development Office. Unpublished.

Goss, S. \& Wahdati, S. (2021). Mid-Term Review of the Climate-Induced Disaster Risk Reduction Project (CDRRP), for UNDP Afghanistan, Final Report. Link

Gunasekara, V. (2020). 'Paradoxes in livelihood interventions: a synthesis of evidence from selected conflict-affected areas in Africa and Asia'. SLRC Working Paper 93. London: Secure Livelihoods Research Consortium. https://securelivelihoods.org/publication/paradoxes-in-livelihood-interventions-a-synthesisof-evidence-from-selected-conflict-affected-areas-in-africa-and-asia/

Huot, D. \& Pain, A. (2017). 'Afghanistan livelihood trajectories: life on the margins in Sar-i-Pul province'. SLRC Working Paper 54. London: Secure Livelihoods Research Consortium. https://securelivelihoods.org/publication/afghanistan-livelihood-trajectories-life-on-themargins-in-sar-i-pul-province/

Hutchens, T.K., Byce, C.N., Monroe, E.G. \& Davis, T.D. (2018). Priorities for investment in public research and extension capacity for improved fodder and forage production in arid and semi-arid Afghanistan. Journal of Arid Land Studies, 28(S), 135-138.

https://doi.org/10.14976/jals.28.S_135

Mallett, R. \& Pain, A. (2018). 'Post -war recovery and the role of markets: policy insights from six years of research'. Global Policy, 9(2), 264-275. https://doi.org/10.1111/1758-5899.12560

Mallet, R. \& Slater, R. (2012). Growth and Livelihoods in Fragile and Conflict-Affected Situations. SLRC Working Paper 9. London: Secure Livelihoods Research Consortium.

https://securelivelihoods.org/wp-content/uploads/SLRC-Growth-and-Livelihoods-in-Fragileand-Conflict-Affected-Situations.pdf

Mallett, R. \& Slater, R. (2016) 'Livelihoods, conflict and aid programming: is the evidence base good enough?'. Disasters, 40(2), 226- 245. https://securelivelihoods.org/publication/liveliho ods-conflict-and-aid-programming-is-the-evidence-base-good-enough/

Maxwell, D., Mazuana, D., Wagner, M. \& Slater, R. (2017) 'Livelihoods, conflict and recovery: findings from the Secure Livelihoods Research Consortium'. London: Secure Livelihoods Research Consortium. https://securelivelihoods.org/wp-content/uploads/Livelihoodsconflict-and-recovery_Findings-from-the-Secure-Livelihoods-Research-Consortium-1.pdf

Pain, A., Jackson, A., Huot, D. \& Minoia, G. (2017) ‘Transforming Afghanistan? Seeking coherence between technical solutions and political processes: lessons from the field'. SLRC Briefing Paper. London: Secure Livelihoods Research Consortium. https://securelivelihoods.org/publication/transforming-afghanistan-seeking-coherencebetween-technical-solutions-and-political-processes-lessons-from-the-field/ 
Shaw, T. \& Ghafoori, I. (2019) 'On borrowed time: the limits of informal credit for livelihood security in Herat, Afghanistan'. SLRC Working Paper. London: Secure Livelihoods Research Consortium. https://securelivelihoods.org/publication/on-borrowed-time-thelimits-of-informal-credit-for-livelihood-security-in-herat-afghanistan/

Stites, E. \& Bushby, K. (2017) 'Livelihood strategies and interventions in fragile and conflictaffected areas: assessing trends and changes from 2012 to 2016'. SLRC Working Paper. London: Secure Livelihoods Research Consortium.

https://securelivelihoods.org/publication/livelihood-strategies-and-interventions-in-fragileand-conflict-affected-areas-assessing-trends-and-changes-from-2012-to-2016/

The Red Cross Red Crescent Climate Centre. (2021). Climate Change Impacts on Health and Livelihoods: Afghanistan Assessment. IFRC. https://www.climatecentre.org/wpcontent/uploads/RCRC_IFRC-Country-assessments-AFGANISTAN.pdf

ThinkClarity. (2020). Building Back Better: Making Sense of Drought and Resilience in Afghanistan. Kabul: UNDP Afghanistan. https://www.af.undp.org/content/afghanistan/en/ho me/library/environment_energy/DrooughtandResilience.html

UNDP Afghanistan. (2019). Final Evaluation of UNDP GEF-LDCF2 Project Afghanistan: Strengthening the resilience of rural livelihood options for Afghan communities in Panjshir, Balkh, Uruzgan and Herat Provinces to manage climate change-induced disaster risks. UNDP PIMS\#: 00087639, GEF Project ID: 5098. Link

World Bank Group \& ADB. (2021). Climate Risk Country Profile: Afghanistan. Washington, DC: The World Bank Group and Manila: Asian Development Bank. https://openknowledge.worldbank.org/handle/10986/36381

\section{Suggested citation}

Price, R.A. (2021). Lessons from livelihood interventions that increase the resilience of populations to droughts in Afghanistan and other FCAS. K4D Helpdesk Report 1067. Institute of Development Studies. DOI:

10.19088/K4D.2022.012

\section{About this report}

This report is based on six days of desk-based research. The K4D research helpdesk provides rapid syntheses of a selection of recent relevant literature and international expert thinking in response to specific questions relating to international development. For any enquiries, contact helpdesk@k4d.info.

K4D services are provided by a consortium of leading organisations working in international development, led by the Institute of Development Studies (IDS), with the Education Development Trust, Itad, University of Leeds Nuffield Centre for International Health and Development, Liverpool School of Tropical Medicine (LSTM), University of Birmingham International Development Department (IDD) and the University of Manchester Humanitarian and Conflict Response Institute (HCRI).

This report was prepared for the UK Government's Foreign, Commonwealth \& Development Office (FCDO) and its partners in support of pro-poor programmes. Except where otherwise stated, it is licensed for non-commercial purposes under the terms of the Open Government Licence v3.0. K4D cannot be held responsible for errors or any consequences arising from the use of information contained in this report. Any views and opinions expressed do not necessarily reflect those of FCDO, K4D or any other contributing organisation.

(C) Crown copyright 2021.

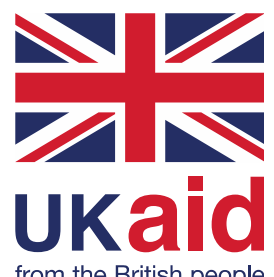

